\title{
Parenteral Nutrition in the Newborn: Associated Disorders and Nutritional Aspects
}

\section{de Abreu Batista $\mathrm{AC}^{1}$ and Freitas $\mathrm{HR}^{*_{2}}$}

${ }^{1}$ Pediatric Medicine Graduate Program, Veiga de Almeida University, R. Ibituruna, 108 - Maracanã - Rio de Janeiro/ RJ, Brazil

${ }^{2}$ Institute of Biophysics Carlos Chagas Filho, Federal University of Rio de Janeiro, Av. Carlos Chagas Filho - Cidade Universitária - Rio de Janeiro/RJ, Brazil

${ }^{*}$ Corresponding author: Freitas HR, Institute of Biophysics Carlos Chagas Filho, Federal University of Rio de Janeiro, Av. Carlos Chagas Filho, Cidade Universitária, Rio de Janeiro - RJ, Brazil, Tel: +55(21)9.8612-2194, E-mail: freitashr@biof.ufrj.br, herculesrezendef@hotmail.com

Citation: de Abreu Batista AC, Freitas HR (2016) Parenteral Nutrition in the Newborn: Associated Disorders and Nutritional Aspects. J Nutr Health Sci 3(1): 106. doi: 10.15744/2393-9060.3.106

Received Date: January 04, 2015 Accepted Date: February 23, 2016 Published Date: February 25, 2016

\begin{abstract}
Severe prematurity at birth is an indicator of additional attention for the multidisciplinary team, since the newborn in this condition did not have the opportunity to develop organic systems under ideal conditions (intrauterine). Several factors may induce premature birth, malformation of organs or metabolic disruptions, however, additional attention has been given to inborn errors of metabolism (IEM) and deficiency/excess of key nutrients. Although relatively rare, IEM are detected in increasingly varied spectra and its importance in the proper fetal development has grown significantly. Variations in nutrient availability are also relate to the functional development of complex structures at the end of fetal development, playing a key role in critical periods of growth. Recent data indicate that an adequate supply of macro and micronutrients during pregnancy may be crucial to the survival of newborns, especially those subject to IEM. The use of parenteral nutrition (PN) in deep affected patients has grown significantly in recent years, and its presence has reduced intensely the morbidity/mortality levels among affected infants. Therapy with PN, however, entails risks to the health of newborns, by either chronic nutritional deficiencies, organ exhaustion or systemic infections. This review aimed to discuss progresses and issues encountered in the treatment of newborns with premature PN.

Keywords: Parenteral Nutrition; Inborn Errors of Metabolism; Malnutrition; Nutritional Therapy

List of Abbreviations: PN: Parenteral nutrition; PNALD: Parenteral nutrition-associated liver disease; CRBSI: Central venous catheterrelated bloodstream infection; CNS: Central nervous system; ANPNC: Australasian Neonatal Parenteral Nutrition Consensus; IEM: Inborn errors of metabolism; GSH: L-glutathione; HCT: Homocysteine; CBS: Cystathionine beta-synthase; MAT I/III: Methionine adenosyltransferase I and III; LCHAD: Long-chain 3-hydroxyacyl-CoA dehydrogenase; BMI: Body mass index; PCD: Primary ciliary dyskinesia; NO: Nitric oxide; ARF: Acute renal failure; USM: Ultrasound methods; MRI: Magnetic resonance imaging; BM: Breast milk; ROP: Retinopathy of prematurity; CLD: Cholestatic liver disease
\end{abstract}

\section{Introduction}

Neonatal complications normally occur due to multifactorial components, which are determinant of the type, gravity and survival rate of the disorder. Currently, premature infant mortality rates are reducing significantly. In the United States, at least $40 \%$ of the newborn with 22 or more gestational weeks are able to survive childbirth (years 1996-2000). During the 80's (years 19811985), this rates of survive were reached only after the 26th gestational week. After surviving, however, premature patients require intensive care, once systemic immaturity imposes a high risk for the occurrence of a large array of complications [1].

Extremely premature patients or those affected by gestational complications may need support from parenteral nutrition (PN), a decisive resource to ensure survival. Parenteral therapy, however, is not a risk free approach. As highlighted by Calkins and colleagues (2014), the use of parenteral nutrition is associated to a myriad of symptoms, especially parenteral nutrition-associated liver disease (PNALD) and central venous catheter-related bloodstream infection (CRBSI) [2]. Nutritional deficiencies are also extenuating factors during PN use, once they impose barriers to the correct development of the central nervous system (CNS), an organ with high levels of plasticity and metabolic activity during the first years of newborn life [3]. 
In 2012, the Australasian Neonatal Parenteral Nutrition Consensus (ANPNC), aiming to reduce costs and attenuate prescription errors, have proposed standardized formulations for parenteral nutrition to intense care newborns. It is possible to highlight some of ANPNC's main orientations, such as: (1) providing up to $150 \mathrm{~mL} / \mathrm{Kg} /$ day of water, including nutrient-containing fluids; (2) caloric content of $100-120 \mathrm{Kcal} / \mathrm{Kg} /$ day to allow for optimal protein-energy adequation or at least $50-60 \mathrm{Kcal} / \mathrm{Kg} / \mathrm{day}$ to fulfill minimum energy needs; (3) $2 \mathrm{~g} / \mathrm{Kg}$ /day amino acids; (4) $17 \mathrm{~g} / \mathrm{Kg} /$ day carbohydrates and; (5) at least 0.5-1.0g/Kg/day lipids [4].

Arginine, an essential amino acid for the biosynthesis of molecules and detoxification of ammonia, is one of the most important in the balance between survival and pathogenesis. Brunton, et al. (1999) have shown that its presence is essential for survival in premature animals, and that the gastrointestinal system is an important regulator of arginine systemic bioavailability [5]. According to $\mathrm{Wu}$ and coworkers (2004), the deficiency of arginine may cause dysfunctions in the cardiovascular, pulmonary, neurological and gastrointestinal systems. Authors highlight that this deficiency occurs due to the limited expression of genes related to the synthesis of citrulline and arginine in intestinal cells, therefore supplementation of these amino acids in PN of premature newborns is a relevant strategy to optimize the nutritional status of these patients [6].

With the emerging increase in the premature pregnancies survival rates, it is essential to homogenize data from the medical literature, allowing accurate therapeutic and nutritional approaches, favorable to the proper development of pediatric patients. This work aims to discuss about the progress and shortcomings encountered in the treatment of premature newborns receiving PN.

\section{Materials and Methods}

To ensure methodological and typographic quality of the collected studies, search procedures were applied according to Freitas, et al. (2015). Search for scientific articles was limited to indexed databases (e.g. PubMed) and high impact journals. The following keywords were selected as search parameters: "Parenteral nutrition"; "Critically ill infants"; "Inborn errors of metabolism"; and "Preterm labor complications". Experimental works, clinical studies and invited reviews were selected preferentially. References from selected documents were also considered for analysis and subsequent use in this work. Excluded items were stored and reevaluated according to the pre-established search procedures. References from non-selected works were also read and additional documents were collected for verification [7].

Experimental studies without explicit presentation of a statement of approval from a responsible ethics committee, or performing inadequate procedures that may impose indiscriminate risk to human and/or animal life, were not considered for the completion of this review. Documents published in non-indexed bases, entertainment magazine articles, blogs, social networks, documents containing unreferenced data and abstracts were automatically excluded. After initial selection, papers were carefully read and classified according to the items and sub-items covered in this study [7]. In "Disorders in neonatology" section, were included works related to inborn errors of metabolism (IEM), respiratory, neurological and electrolyte disorders. In "Nutritional aspects", were selected documents related to nutritional needs and therapeutic approaches, in addition to nutritional deficiencies common to critical infants. In "Parenteral nutrition", data on the composition, use and complications of PN were included.

\section{Selection criteria}

Articles were excluded if not met the following inclusion criteria: neonatology-associated disorders OR physiological, neurological and metabolic disorders OR nutritional aspects of prematurity AND parenteral nutrition AND newborn or infant individuals, except for studies using in vivo (non-human) and in vitro experimental models, which were also considered for the purposes of this review. This study followed three major stages of document analysis:

1. Search for keywords in indexed databases and printed issues ( $\mathrm{n}>3000$ documents);

2. Analysis title and summary, to exclude unrelated studies ( $\mathrm{n}=435$ documents);

3. Careful selection, followed by individual articles reading $(\mathrm{n}=70$ documents).

Due to the large number of initial documents, we used software (Zotero Standalone 4.0) to organize and select references. Considering the methodological limitations of this narrative review, we have adapted our search procedures from Freitas, et al. (2015) and from the PRISMA (i.e. Preferring Reporting Items for Systematic Reviews and Meta-Analyses) norms and standards, allowing for systematic search, optimization of analysis and discussion of the data obtained [7]. Figure 1 illustrates the procedures followed for document acquisition, selection and evaluation. 


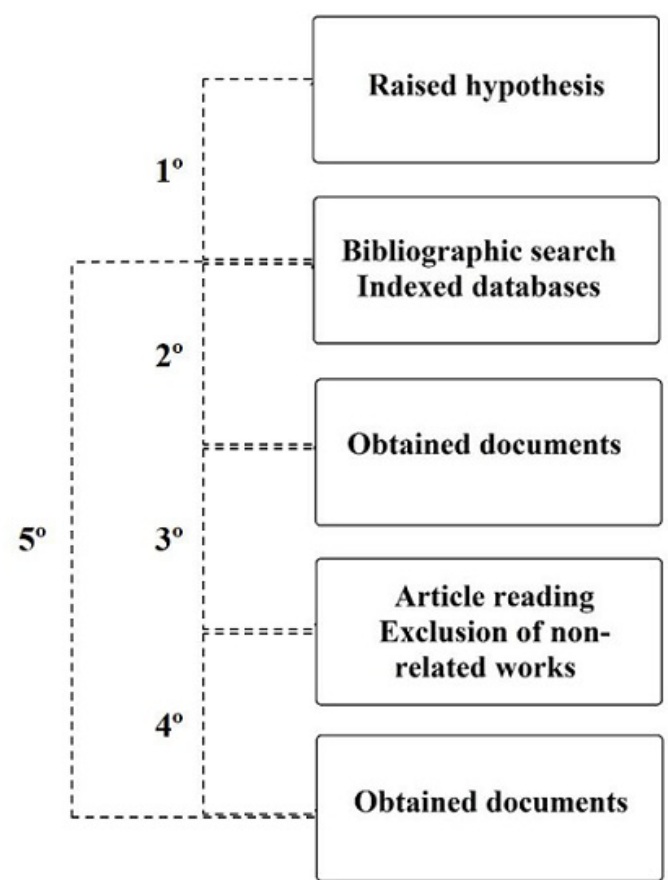

${ }^{\star}\left(1^{\circ}\right)$ after raising a hypothesis, search parameters were determined and scientific documents searched within indexed databases. $\left(2^{\circ}\right)$ Obtained documents $\left(3^{\circ}\right)$ were read in full and non-related/low quality works were excluded. $\left(4^{\circ}\right)$ Final group of documents were obtained $\left(5^{\circ}\right)$ and the process repeated during the period for data analysis to ensure the inclusion of newly published works. Adapted from [7]

Figure 1: Bibliographic search and inclusion steps

\section{Results and Discussions}

\section{Disorders in neonatology}

The complexity of the known IEM presents a major challenge for the practice of pediatrics, which makes early diagnosis of the most useful tools in preventing sequelae or death in intensive care patients. Among the most common consequences of IEM are the acute metabolic encephalopathy, hyperammonemia, metabolic acidosis, and hepatic dysfunction of glucose metabolism. Manifestations related to IEM are intricately structured, and customarily results in a set of relatively similar symptoms [8]. In recent years, researchers around the world have sought to characterize the wide range of IEM. To this end, several mass spectrometric methods have been used [9-11].

A great variety of symptomatic IEM is caused by the possibility of different levels of expression and activity of several enzymes. As example are the errors associated with the metabolism of L-glutathione (GSH), a tri-peptide made of glutamate, cysteine and glycine residues, which are present at millimolar concentrations in virtually every cell of the body. GSH is involved in several fundamental biological activities, especially working as non-enzymatic antioxidant, intra and extracellularly. Of the six enzymes involved in the metabolism of GSH, five are related to known IEM, the residual enzymatic capacity and viability of other associated enzymes determines the severity of the symptoms presented, such as hemolytic anemia, metabolic acidosis, neuromuscular defects and generalized aminoaciduria [12].

Among the disorders related to amino acids, those involved in sulfur amino acid metabolism should receive additional attention. Defects in the methionine cycle are involved in methionine synthase activity, either by disorders in the synthesis of cobalamin due to abnormalities in the apoenzyme, and consequently a failure in the formation of methyltetrahydrofolate, or by defects in the enzyme methionine synthase. All these errors dramatically increase homocysteine (HCT) levels, toxic to the body in high concentrations. Other disorders can significantly raise HCT levels are: the deficiency of the enzymes cystathionine beta-synthase (CBS); cystathionase; methionine adenosyltransferase I and III (MAT I/III); glycine N-methyltransferase; and S-adenosylhomocysteine hydrolase. Apparently, patients presenting any of these disorders respond positively to a methionine restricted diet, indicating that patients under restricted PN presenting these IEM must receive a different combination of amino acids [13].

It is possible, however, that other EIM are involved in the defective metabolism of HCT. Cobalamin deficiency is associated with increased and accumulation levels of methylmalonic acid and HCT. Although dietary deficiency of this and other organometals is rare, there are altogether twenty IEM that can affect the absorption, transport, uptake or intracellular metabolism of cobalamin. A major dysfunction to be highlighted is the deficiency in the synthesis of intrinsic factor, essential for the proper absorption of cobalamin. Specific symptoms of the disease appear when the patient is between 1-5 years of age, however, there is the possibility that megaloblastic anemia and/or neurological problems appears before this period [14]. 
Leonard and Morris (2000), in an exceptional literature review, highlights the various manifestations of IEM presented during pregnancy, birth and early postpartum period (2-3 days). According to the authors, women with fetuses presenting deficiencies in the enzyme long-chain 3-hydroxyacyl-CoA dehydrogenase (LCHAD) are likely to develop disorders such as hemolysis, high levels of liver enzymes and low platelet count. At birth, common symptoms related to the presence of IEM are: (1) neuromotor dysfunction, severe hypotonia, ascites and dysmorphic syndromes. Abnormalities of neurological origin, caused by congenital lactic acidosis, are often confused with perinatal asphyxia in this period. Defects in fatty acid oxidation in the postpartum period are usually the cause of death by respiratory failure or venous blockage [15].

Data reinforces the need for the use of efficient diagnostic tools in gestational and early postnatal periods. Various manifestations can be associated with IEM and therefore allow for therapeutic approach toward drug or nutritional correction of the disorder. Patients under PN treatment alone should receive additional attention in this context, as small changes in the levels of nutrients and caloric content can influence the survival and further development of the infant. Table 1 shows various symptoms commonly associated with IEM.

\begin{tabular}{|c|c|}
\hline Diarrhea & $\begin{array}{c}\text { Lactase deficiency } \\
\text { Mitochondrial disorders* } \\
\text { Abetalipoproteinemia } \\
\text { Enteropeptidase deficiency } \\
\text { Lysinuric protein intolerance } \\
\text { Sucrase/isomaltase deficiency } \\
\end{array}$ \\
\hline Intolerance to exercises & $\begin{array}{l}\text { Fatty acids oxidation disorders } \\
\text { Glycogenolysis disorders } \\
\text { Mitochondrial disorders* } \\
\text { Myoadenylate deaminase deficiency }\end{array}$ \\
\hline Myocardial infarction & $\begin{array}{c}\text { 5,10-methylenetetrahydrofolate reductase deficiency Famil- } \\
\text { ial hypercholesterolemia } \\
\text { Fabry disease } \\
\text { Homocystinuria }\end{array}$ \\
\hline Muscle spasms & $\begin{array}{c}\text { Multiple deficiency of carboxylase } \\
\text { Metachromatic leukodystrophy } \\
\text { HHH syndrome }\end{array}$ \\
\hline Peripheral neuropathy & $\begin{array}{l}\text { Mitochondrial disorders* } \\
\text { Peroxisomal disorders } \\
\text { Metachromatic leukodystrophy } \\
\text { Genetic disorders of glycosylation }\end{array}$ \\
\hline Recurrent emesis & $\begin{array}{c}\text { Galactosemia } \\
\text { 3-oxothiolase deficiency } \\
\text { d-2-hydroxyglutaric aciduria }\end{array}$ \\
\hline Pancreatitis symptoms & $\begin{array}{c}\text { Mitochondrial disorders* } \\
\text { Type I glycogenosis } \\
\text { Types I and IV hyperlipoproteinemia } \\
\text { Lipoprotein lipase deficiency } \\
\text { Lysinuric protein intolerance }\end{array}$ \\
\hline Eye muscle paralysis & $\begin{array}{l}\text { Mitochondrial disorders* } \\
\text { Type C Niemann-Pick disease }\end{array}$ \\
\hline
\end{tabular}

${ }^{*}$ Disorders of mitochondrial etiology may be related to respiratory chain components, oxidation of lipids and various other components of the organelle. Adapted from [16]

Table 1: Symptoms associated to inborn errors of metabolism

In large populations, the fatality rate related to respiratory disorders is relatively low, however, there is a wide variety of affections capable to impose health risks to preterm infants or newborns from mothers whose age is inadequate for pregnancy. Rubaltelli, et al. (1998) investigated a population of approximately 17,000 Italian neonates, of these, about 2.8\% has developed some signal of respiratory distress, and $15.88 \%$ were cases of fatality. The fatality rate by respiratory disorders, in any population observed, was $0.45 \%[17]$.

According to Levine, et al. (2001), the incidence of pulmonary hypertension in neonates is about five times greater in individuals born by cesarean compared to the traditional delivery procedure [18]. Several authors have investigated the consequences of a cesarean delivery, such as the occurrence of uterine rupture [19]. In addition, recent data suggest that this mode of delivery can significantly affect the body mass index (BMI) of these subjects when adults (23-25 years), without, however, the presence of other metabolic risk markers [20].

Performing of cesarean delivery have increased significantly over the years, about $37 \%$ of US births are performed this way [21]. When the procedure (i.e. cesarean) is the mother's choice, a responsible medical team has to inform the patient about the risks and benefits of the procedure. In fact, recent results indicate that the mother's reproductive plans are a key factor in the successful development of the gestational process, whatever the mode of delivery selected by the family [22]. 
Genetic and epigenetic disorders can affect respiratory function in the postnatal period; such disorders are greatly influenced by behavioral factors and family history. As expected, infants requiring intensive care often present a variated array of hereditary dysfunctions. Data about inaccuracies in the expression of alleles of the surfactant protein $\mathrm{A}$ are heterogeneous, but indicate that this protein is related to adequate protection against viral and bacterial infections. Surfactant proteins C and D, in contrast, appear to be involved in the development of chronic affections. Loss of function in alleles expressing the surfactant protein B seems to have greater impact on postnatal affections, potentially generating irreversible acute or chronic effects in susceptible infants [23].

Primary ciliary dyskinesia (PCD) is an autosomal recessive hereditary manifestation resulting in inappropriate mucociliary transport, characterized by airway obstruction and recurrent infections of the lung, middle ear and paranasal sinuses. Individuals with PCD normally live satisfactorily if treated with the appropriate periodicity, however, there is certain degree of unpredictability in the progression of the symptoms, which can result in severe pulmonary dysfunction and, ultimately, to respiratory failure and death [24].

Pharmacological approaches at the end of pregnancy (34-36 weeks) and in the postpartum period are apparently ineffective in mitigating the incidence of inflammatory or dysplastic airway diseases. Porto, Coutinho and Amorim (2011), after administration of $12 \mathrm{mg}$ intramuscular betamethasone in pregnant women with imminent risk of having premature delivery, found no reduction in the incidence of respiratory disorders in neonates [25]. Kinsella and colleagues (2006) also found no reduction in the incidence of bronchopulmonary dysplasia in infants with birth weight $>1000 \mathrm{~g}$ after the administration of nitric oxide (NO). Their data, however, indicate that the use of NO was able prevent overall risk of brain damage [26].

Extremely premature infants may undergo major loss of water and electrolytes, this is mainly due to disproportion between the relatively large body surface area and the immaturity of their skin. This relationship allows insensible water loss, which can be exhausted in the presence of other factors such as radiant heat, tachypnea, omphalocele, gastroschisis and exposure to dry conditions. According Bhatia (2006), six strategies may be used for proper maintenance of fluid and electrolytes in premature infants with body weight under 1000g: (1) effective parenteral delivery of amino acids; (2) proper fluid replacement; (3) continuous measurement of electrolytes; (4) progressive increase in amino acid supply; (5) adjustment of lipids supply and; (6) monitor weight, vital signs and plasma urea daily, providing sodium (2-3mEq/kg/day) only when measured under $130 \mathrm{mEq} / \mathrm{L}$, plus $2-3 / \mathrm{kg} /$ day of potassium [27].

In addition to the regular continued attention needed to maintain the health of the newborn, diseases and dysfunctions of hereditary nature may induce electrolyte imbalance in premature and at term infants. Acute renal failure (ARF) may occur due to a congenital etiology, as in the case of polycystic kidney disease. This disorder can also occur in the postnatal period as a result of ischemic hypoxia or severe toxicity induced by chemical contaminants or IEM/drugs [28]. Gouyon and Guignard (2000) discuss procedures needed for the application of intense care in neonates with ARF. According to authors, the initial treatment of complications related to ARF should aim to correct the hypotensive crisis, acidosis and hypoxemia, allowing reduced renal vasoconstriction and improved tissue perfusion [29].

Infants with less than 3 months of age, in which the formation of the urinary tract was inadequate, in concomitance to pyelonephritis, are at risk of transitional pseudoaldosteronism. Thies, et al. (1999) report the case of newborn males, 17 days of life, which presented with pseudoaldosteronism as consequence of pyelonephritis and vesicoureteral reflux. The initial diagnosis, however, was congenital adrenal hyperplasia, characteristic of the symptoms of insensitivity to aldosterone and excessive loss of sodium [30]. Martinerie, et al. (2009), however, describing physiological mechanisms of interaction between aldosterone and excretion of electrolytes in the postpartum period, point out that the emergence of partial resistance to aldosterone action is common in the first moments of life [31], indicating that additional markers such as intense metabolic acidosis and dehydration should be added to the diagnostic process.

According to recent data from Diogo, et al. (2015), metabolic and electrolyte disorders in newborns cause damage to the CNS, preferably originating in the deep region of the gray matter, with less involvement of the white matter and cortical regions. These lesions are typically bilateral and symmetrical, with the exception of non-keto hyperglycemia, which is typically unilateral [32]. Neurological disorders in newborns will be briefly discussed next.

The evaluation of neurodevelopmental status is one of the most critical remarks to be held in the first days after birth [33]. Since the middle of the ninth century, authors have recognized the need to evaluate physical parameters, such as the signals for the adequate development of the nervous system. During this period, aspects such as quality of hair, skin and plantar creases served as clinical evidence for neurological maturity [34]. Recent studies indicate that even discrete neurological signs serve as a parameter for assessing the presence of cognitive and psychiatric disorders in newborns, especially those with low birth weight [35]. It is necessary, therefore, that grading standards are clear about the etiology and severity of the presented neurological dysfunction, allowing emergency therapeutic procedures to be more effective [36]. 
In addition to intrinsic factors, environmental factors and maternal quality of life during pregnancy can result in observable neurological disorders. In a prospective observational study, Smith and colleagues (2000) evaluated the neuropsychological performance of newborns born from pregnant women with subclinical hypo or hyperthyroidism. Their data indicate that in the first half of pregnancy, the presence of subclinical hypothyroidism was associated with lower mental development index during the first year of life [37]. Chiriboga, et al. (1999) investigated the neurological effects of fetal exposure to cocaine in about 100 newborns whose mothers were regular users of different doses of the substance. Drug-exposed children have high rates of growth retardation, smaller head circumference and neurological abnormalities, such as global hypertension, tremors and stiffness in the extensor muscle. Using linear regression analysis, the authors also showed that the extent of neurologic damage occurred in a dose-dependent manner [38].

According to Dammann, et al. (2015), damage to the lungs and brain are the most common affections found in immature neonates. In cortical regions, there was extensive damage to white matter, including focal necrosis and diffuse astrocytosis. Ultrasound methods (USM) are typically used for detection of large histological injury areas, however, only about $8 \%$ of infants born with very low birth weight $(<1500 \mathrm{~g})$ show observable signs of tissue injury. Methods such as magnetic resonance imaging (MRI), however, are able to detect indicators of morphological abnormalities in about 50\% of individuals born before 34 gestational weeks [39]. Data corroborate concisely about the accuracy of MRI methods [40]. In addition, epidemiological studies indicate that preterm $(<32$ weeks) and extremely low birth weight $(<1500 \mathrm{~g})$ individuals exhibit high levels of cognitive impairment and have great difficulty in becoming completely independent of familial care [39].

In a recent study, Miller and colleagues (2007) showed that congenital cardiovascular diseases are correlated with abnormal morphological brain development. Their data suggest similarity with results from preterm infants, born with extremely low birth weight, presenting significant increase in tissue diffusivity and loss of white matter [41]. Recent data suggest that treatment with low doses of recombinant human erythropoietin is capable of reducing risk of morphological and functional disorder in neonates with moderate hypoxic-ischemic encephalopathy [42]. These data indicate that severe hypoxemia and vascular disorders produce potentially irreversible morphologic damage in premature neonates, stressing the need for effective and sensitive diagnostic tools during pregnancy.

As previously discussed, there is a need to develop effective tools for diagnosing diseases initiated during pregnancy. Due to very specific mechanisms and phenotypes expressed, however, researchers are struggling to find effectively predictive methods for unusual neurological diseases [43]. Currently, authors investigate the role of mitochondrial dynamics in neuroplasticity and development of neurological diseases [44], searching, through the use of stable clonal lineages of neural stem cells, new methods in regenerative medicine for the central tissue [45].

\section{Nutritional aspects}

After birth, dramatic changes in energy metabolism occur in order to ensure proper body development, especially the essential consolidation of CNS structures, which takes many years to reach some level of stability. In premature newborns, these nutritional requirements not only overdrive, but also create a differentiated demand for protein, total calories and key minerals, such as calcium. Recommendations for caloric intake to low birth weight infants (i.e. $120 \mathrm{Kcal} / \mathrm{kg} / \mathrm{day}$ ) have remained unchanged for 30 years $[4,46]$. Authors have, however, revalued guidelines on protein requirements, considering this nutrient a limiting factor for the proper development of premature newborns. Rigo and Senterre (2006) highlighting the role of protein on weight gain, growth stimulus and accumulation of lean mass, recommends about 3.8-4.4g of protein $/ \mathrm{kg} /$ day and protein/energy ratio of about $3.0-3.3 \mathrm{~g} / 100 \mathrm{kcal} /$ day for preterm infants with $26-30$ weeks of age [47].

The use of breast milk (BM) is essential for proper development of the newborn, and recent data suggest that preterm infants may benefit from approaches where the provision of BM in complemented with nutritional therapy. Authors point out that the use of BM promotes gastrointestinal maturation processes, improvements in neurobehavioral tests, optimized coordination of sucking/ swallowing, oxygen saturation and body temperature, indicating that feeding premature infants with BM comprises a physiological recovery strategy [48]. The use of BM has also been explored as a way to counter approaches with strictly unnatural food, that despite the ability to promote improvements in growth and calorie intake, does not optimize survival rates or decrease the length of stay under hospital care [49]. Therefore, it's of great importance to highlight the need for early observation of malnutrition and prematurity signs, once this practice may shorten the demand for permanence under hospital care, PN therapy and even invasive procedures.

In newborns receiving enteral or $\mathrm{PN}$, attention should be paid to the adequate supply of essential nutrients and the recovery from symptoms of congenital affections, such as IEM. VanderVeen, et al. (2013) show that limited supply of essential nutrients, especially lipids and, therefore, total calories, may exhaust symptoms of retinopathy of prematurity (ROP). Data indicate that weight gain is a key approach to reduce symptoms of ROP in extremely premature infants [50]. In fact, recent data indicate that parenterallyprovided lipids to premature infants with extremely low birth weight is related to weight gain and possibly optimize the nutritional status during the intensive care period [51]. With the advent of new technologies in the production of concentrated/isolated food compounds for nutritional therapy, investigators seek to highlight the participation of specific lipids in the recovery of several bouts. Recent evidence indicates that long-chain polyunsaturated fatty acids play an important role in the treatment of IEM [52] and morphological development of the CNS [53]. 
A problem faced by nutritional approaches in pre or postnatal periods is that, in many cases, damage or delay in the development and differentiation of cells in the CNS makes it impossible to restore proper cognitive state during childhood and adulthood. Gestational periods where proliferation of neural cells is critical seem to be crucial in the morphofunctional consolidation of brain structures and thus prevents drastic recovery or induction of plasticity only by nutritional approaches during or after birth [54]. Due to the prematurity of certain disorders, the use of PN can act only as a stopgap measure, losing its essentiality or ability to promote improvements in the framework of profoundly affected newborns. These cases require deep ethical reflection, in order to provide parents or guardians with the best guidance about the non-effectiveness of PN and therefore the interruption of its use [55].

Nutritional deficiencies during pregnancy may impose profound impact on the proper fetal development, and also affect the emergence of symptoms related to weight disorders in adulthood. Triunfo and Lanzone (2015) highlight aspects of malnutrition in the prenatal period and its direct consequences at birth. According to authors, cases of gestational iron-deficiency anemia can induce premature labor, prolonged labor, postpartum hemorrhage and also fetal growth restriction. Vitamin A deficiency, in turn, can promote episodes of maternal night blindness, low birth weight, reduced growth rate and raise the mortality/morbidity levels of infants [56]. Evidence suggests that, while some of the damage may occur prior to birth, supplementation with micronutrients through PN would promote total or partial recovery from symptoms or nutrient deficiencies (see Table 3).

Zinc, a key micronutrient for essential cellular functions, seems to be an important factor in preventing premature births. It's also common to observe the development of cretinism in the offspring of women presenting severe iodine deficiency. This disorder, however, can be eliminated with supplementation during the first trimester of pregnancy or during the prenatal period. The lack of folate may prevent proper formation of the neural tube, with serious impacts on morbidity/mortality. Finally, calcium deficiency was related to hypertensive disorders during pregnancy, mortality, premature birth, fetal growth restriction and also those related disorders of vitamin D metabolism [56].

In a recent study, Sonne, et al. (2012) developed neonate mice with mutations in the OCTN2 carnitine transporter, which plays an important role in carnitine resorption, accounting for over $90 \%$ of the carnitine transport capacity to body tissues. Data show severe morphological changes in the intestinal epithelium, infiltration of lymphocytes and macrophages, generalized atrophy, proapoptosis and inflammatory responses [57]. Failure of expression or deficiency of carriers for certain nutrients is a causal factor for many disorders in newborns, especially in premature ones. Deficiencies in the expression of an intestinal zinc transporter (i.e. ZIP4), for example, leads to severe zinc malabsorption, which performs its biological function at picomolar (pM) concentrations. This deficiency, when chronic, causes acrodermatitis enteropathica, a recessive inherited disease that imposes severe damage to epithelia and other systems [58].

In an epidemiological study by McLimore and colleagues (2013), multiple risk factors (intrinsic and environmental) proved to be proportionally correlated to the adequacy of iron in the postnatal period, indicating that nutritional deficiencies can be influenced by factors other than those traditionally observed [59]. Maldonado-Cedillo and colleagues (2015), in turn, have recently demonstrated that malnutrition may extenuate other phenomena responsible for inducing fetal developmental disorders. In their study on rodents, the use of a malnutrition protocol with lead poisoning led to reduced body and brain weight from the fourth week of pregnancy, significant increases in lipid peroxidation and increased stress-like activity in cerebellar regions [60].

Malnutrition during critical periods of gestation can also negatively regulate the expression of genes related to development and child growth. Ojha, et al. (2013), in a model of sheep, showed that the supply of sub-optimal feeding to pregnant animals led to lower expression of genes related to the activity of the brown adipose tissue, which is intrinsically involved with substrate metabolism during the initial periods of mammal development [61]. Current trends in nutrition of premature infants indicate that it is imperative that mothers aim to provide BM as the main nutrient source, with or without additional nutritional therapy, unless it's necessary to guarantee the required substrates for postnatal growth [62]. Authors also highlight the importance of observing the specificity in the supply of key nutrients, ensuring that the minimum needs for polyunsaturated chain fatty acids are adequate, and that the iron supply, necessary to balance oxygen perfusion systems and nutrients throughout the body, is preserved [63].

\section{Parenteral Nutrition}

The supply of PN is, in first instance, a mandatory procedure to balance nutrient losses and imbalances caused by diseases capable of impairing oral feeding. Even if PN is not able to fully replace the nutritional needs of premature newborns, its use prevents morbidity and mortality in several infants in critical condition. IEM patients, for instance, have a mandatory need for specific amino acids, lipids and other derivatives to be supplemented or definitively excluded from their diet, therefore PN may be used to provide with essential nutrients, absent in a restrictive diet. Infants with extreme low birth weight presenting with respiratory complications, however, may demand greater caloric input, which is frequently impaired due to the prematurity of digestive mechanisms, intestinal epithelium and liver. Premature newborns at risk of developing neurological disorders, such as cognitive impairment and/or extensive neural/glial death may receive parenteral support to provide polyunsaturated fatty acids, micronutrients and energy necessary to allow for neuronal growth, survival and differentiation. Finally, preventing loss or excessive accumulation of electrolytes is one of the most essential uses of PN, once it's able to prevent CNS injuries and compensate for irregular reabsorption/excretion of several micronutrients. Table 2 presents nutrient recommendations (via PN) for high-risk newborns. 


\begin{tabular}{|c|c|}
\hline Nutrient & Estimated needs \\
\hline Calorie (kcal/kg) & $80-90$ \\
\hline Carbohydrates (g/kg) & 16 \\
\hline Proteins $(\mathrm{g} / \mathrm{kg})$ & $3-4^{*}$ \\
\hline Lipids $(\mathrm{g} / \mathrm{kg})$ & $3-4$ \\
\hline Sodium $(\mathbf{m E q} / \mathbf{k g})$ & $3-4^{*}$ \\
\hline Potassium (mEq/kg) & $2-4$ \\
\hline Calcium (mg/kg) & $80-120$ \\
\hline Phosphorus (mg/kg) & $60-90$ \\
\hline Magnesium (mg/kg) & $9-10$ \\
\hline Copper $(\mathrm{g} / \mathrm{kg})$ & 65 \\
\hline Zinc (g/kg) & $350-450^{*}$ \\
\hline Vitamin A (IU/kg) & 500 \\
\hline Vitamin D (IU/kg) & 160 \\
\hline Vitamin E (IU/kg) & 2.8 \\
\hline Vitamin K (IU/kg) & 80 \\
\hline Vitamin B1 (mg/kg) & 350 \\
\hline Vitamin B2 (mg/kg) & 150 \\
\hline Niacin (NE/kg) & 6.8 \\
\hline Vitamin B12 (g/kg) & 0.4 \\
\hline Vitamin C (mg/kg) & 32 \\
\hline
\end{tabular}

${ }^{*}$ Ileostomy, surgical drain and other procedures may result in increase in demand. Adapted from $[64]$

Table 2: Nutritional recommendations for parenteral nutrition in high-risk newborns

Prior to the availability of PN, premature children and high-risk pregnancy had lower rates of survival. With its emergence and subsequent adaptation for neonates, there was a drastic increase in survival and clinical evolution, even in high-risk infants. On should, however, to consider the use of NP as an emergency feature, which imposes significant side effects to the neonate and also involves significant hospital costs. PN standardized solutions usually consist of dextrose, as a source of carbohydrate; essential and non-essential amino acids, thus mimicking protein intake orally; fat emulsions, providing essential polyunsaturated lipids and fatty acids as an energy source; carnitine to promote the oxidation of long chain fatty acids; sodium, calcium and phosphorus, essential electrolytes; vitamins and trace elements, which can vary according to symptoms or procedures to which the infant is subjected [64]. Table 3 presents a brief example of neonate progression through PN and possible modifications according to specific needs and disorders.

\begin{tabular}{|c|c|c|}
\hline $0-24 h$ & Day 2 & Days 3-7 \\
\hline $\begin{array}{l}\text { - Glucose } 6-8 \mathrm{mg} / \mathrm{Kg} / \mathrm{min} \\
\text { - Amino acids } 3 \mathrm{~g} / \mathrm{Kg} \\
\text { - Calcium } \\
\text { - Fat } 0.5-1 \mathrm{~g} / \mathrm{Kg} / \text { day }\end{array}$ & $\begin{array}{l}\text { - Glucose } 6-8 \mathrm{mg} / \mathrm{Kg} / \mathrm{min} \\
\text { - Amino acids 3-3.5 g/Kg } \\
\text { - Calcium } \\
\text { - Electrolytes } \\
\text { - Fat } 0.5-1 \mathrm{~g} / \mathrm{Kg} / \text { day }\end{array}$ & $\begin{array}{l}\text { - Glucose increase to goal of } 11-13 \mathrm{mg} / \mathrm{Kg} / \mathrm{min} \\
\text { - Amino acids } 3 \mathrm{~g} / \mathrm{Kg} \\
\text { - Calcium } \\
\text { - Electrolytes } \\
\text { - Phosphorus } \\
\text { - Vitamins } \\
\text { - Trace elements } \\
\text { - Fat increase to goal of } 3-4 \mathrm{~g} / \mathrm{Kg} / \text { day }\end{array}$ \\
\hline Day 7 & Week 2 & Variable requirements \\
\hline $\begin{array}{l}\text { - Glucose goal of } 11-13 \mathrm{mg} / \mathrm{Kg} / \mathrm{min} \\
\text { - Amino acids } 3 \mathrm{~g} / \mathrm{Kg} \\
\text { - Calcium } \\
\text { - Electrolytes } \\
\text { - Phosphorus } \\
\text { - Vitamins } \\
\text { - Trace elements } \\
\text { - Fat goal of } 3-4 \mathrm{~g} / \mathrm{Kg} / \text { day }\end{array}$ & $\begin{array}{l}\text { - Glucose goal of } 11-13 \mathrm{mg} / \mathrm{Kg} / \mathrm{min} \\
\text { - Amino acids } 3 \mathrm{~g} / \mathrm{Kg} \\
\text { - Calcium } \\
\text { - Electrolytes } \\
\text { - Phosphorus } \\
\text { - Vitamins } \\
\text { - Trace elements } \\
\text { - Fat goal of } 3-4 \mathrm{~g} / \mathrm{Kg} / \text { day } \\
\text { - Carnitine } 5 \mathrm{mg} / \mathrm{Kg}\end{array}$ & $\begin{array}{l}\text { - Extremely low birth weight: increase goal fat and } \\
\text { calories } \\
\text { - Growth restriction: polyunsaturated fatty acids, } \\
\text { iron and total calories } \\
\text { - IEM* and CNS }{ }^{* *} \text { malformations: increase long- } \\
\text { chain polyunsaturated fatty acids } \\
\text { - Dehydration: Fluid and electrolyte replacement } \\
\text { - IEM*: remove/increase amino acids (i.e. } \\
\text { tryptophan) and carnitine } \\
\text { - Anemia and low oxygen perfusion: Iron sup- } \\
\text { plementation } \\
\text { - Pseudoaldosteronism: Sodium replacement } \\
\text { - Retinopathy of prematurity: increase goal fat and } \\
\text { calories }\end{array}$ \\
\hline
\end{tabular}

${ }^{\star}$ Inborn errors of metabolism. ${ }^{\star \star}$ Central nervous system. Adapted from [30], [46], [47], [63] and [64]

Table 3: Variable requirements in neonate progression through parenteral nutrition (PN) 
Several authors discuss the need for using individualized PN prescriptions, considering the availability of novel automated systems, that do not require daily evaluation and can automatically modulate the availability of nutrients needed for critical patients. According to Beecroft, Puntis and Martin (1999), Yeung, et al. (2003) and a review from Riskin, Shiff and Shamir (2006), the use of standardized prescriptions apparently doesn't induce significant changes in biochemical standards, and promotes a significant reduction in error rates, also attenuating total expenses with therapeutic procedures. Authors also point out that the use of computerized systems for the administration of nutrients may optimize this procedure [65-68].

As regards the micronutrients, small changes in their supply may modulate common disorders of patients undergoing therapy with PN. There is hard debate on whether is needed to fine-tune the standardization of nutritional formulas for PN, however, few clinical evidences are collected on these matter. The provision of chromium (Cr), for example, has been reported as excessive by recent studies, whereas only contaminants in PN solution may increase from 10-100\% metal concentrations in the administered compound [69]. Manganese (Mn), in turn, is a trace element found in virtually all tissues, playing roles related to the metabolism of macromolecules/nutrients as an allosteric modulator, acting through a large family of enzymes related to these pathways. Studies indicate that, despite its essentiality, the removal of Mn solutions from PN may benefit patients with cholestatic liver disease (CLD), even in those infant patients who develop symptoms at the expense of PN therapy chronicity [70,71].

Similarly to $\mathrm{Mn}$, copper $(\mathrm{Cu})$ is an essential nutrient, even in low concentrations, which should be present in the food or therapeutic solution in order to avoid symptoms of anemia, neutropenia, skeletal abnormalities, and other clinical manifestations. Evidence point, however, to the need for reducing the concentration of $\mathrm{Cu}$ in $\mathrm{PN}$ solutions for infants and children presenting CLD [72]. Corrections in the levels of potentially harmful nutrients and contaminants may help to improve the general framework of premature infants, thus avoiding specific symptoms developed during pregnancy. Authors, however, have not yet been able to demonstrate improvements in the general health of affected newborns by providing supplemental nutrients thought to be beneficial. A study of glutamine supplementation was not able to induce significant improvements in neonates and infants undergoing surgery in the digestive tract [73], reinforcing the idea that protocols that prioritize standardization of regulations, adequate supply of needed nutrients and prevention of deficiencies are the best to optimize neonate survival.

One of the main complications related to the use of PN are those associated with the liver, about 40-60\% of infant patients undergoing PN for long periods develop PNALD. Among the common liver onsets are: hepatic steatosis, cholestasis, deficiency of nutrients and diseases associated with the gallbladder. Oral decontamination, encouraging enteral feeding, fiber intake and treating catheters with antibiotics are among the most common strategies to prevent or treat PNALD [74], however, these procedures must follow a strict schedule, considering that the period for permanence under PN support may not last for more than few weeks, once a long-term use of PN implies in elevated risk of infection, organ failure and death. In these cases, the family must consider the possibility of either an induced recovery through oral/enteral feeding or an invasive procedure, such as gastrostomy.

Recent evidence, including original articles and case reports point to the use of lipid emulsions containing fish oil as a resource to prevent and even reverse PNALD. De Meijer, et al. (2009) presented data indicating that treatment with emulsions containing fish oil may revert hepatic onsets in a murine model [75], while Gura, et al. (2006) report two cases where infants with intestinal failure were treated with omega-3 fatty acids. One patient could be withdrawn from a transplant list, while the second was completely free of symptoms of cholestasis [76]. These data point to the importance of exploring the effects of lipid emulsions enriched with fatty acids, especially long chain n-3 polyunsaturated fatty acids and its derivatives.

As discussed above, one approach to reduce liver symptoms is the treatment of PN catheters with antibiotics and, in some cases, its periodic replacement. Catheter-related bloodstream infections are common, and must be primarily prevented by proper handling during exchange and maintenance of both catheter and perfusion systems. According to Puntis and Hodge (2002), some procedures may be applied to prevent contamination and related infections of the PN catheter, such as: (1) installation and handling of the catheter by experienced operators; (2) use of catheter as a route passage of nutrient solutions only; (3) use of preplanned treatment protocols and; (4) continuous training of the critical care team and multidisciplinary professionals [77].

\section{Conclusions}

Hereditary or environmental factors may affect proper fetal development and induce prematurity of systems. In those cases, susceptibility to nutritional deficiencies, infections, and other physiological disorders are increased. High risk of prematurity may require treatment with $\mathrm{PN}$ to delayed or reverse symptoms, allowing greater chance of survival and quality of life in adulthood. Some disorders, however, occur in critical periods of fetal development and therefore may be irreversible, resulting in ethical conflict regarding the maintenance of $\mathrm{PN}$ in patients without positive perspective of progression. The medical team should therefore use technical information and based-on-evidence arguments to provide parents with better advice about the maintenance of PN therapy. PN is a resource able to significantly mitigate the levels of child mortality and morbidity, and has been enhanced with the use of precise technological resources and studies that regulate the real nutritional requirements of deeply affected patients, avoiding shortages and induction of toxicity on fragile systems. 


\section{Acknowledgements}

Authors proudly acknowledge funding support from Coordenação de Aperfeiçoamento de Pessoal de Nível Superior (CAPES).

\section{References}

1. Ward R, Beachy JC (2003) Neonatal complications following preterm birth. BJOG 110: 8-16.

2. Calkins KL, Venick RS, Devaskar SU (2014) Complications Associated with Parenteral Nutrition in the Neonate. Clin Perinatol 41: 331-45.

3. Pickler RH, McGrath JM, Reyna BA, McCain N, Lewis M, et al. (2010) A Model of Neurodevelopmental Risk and Protection for Preterm Infants: J Perinat Neonatal Nurs 24: 356-65.

4. Bolisetty S, Osborn D, Sinn J, Lui K (2014) Standardised neonatal parenteral nutrition formulations-an Australasian group consensus 2012. BMC Pediatr 14: 48.

5. Brunton JA, Bertolo RF, Pencharz PB, Ball RO (1999) Proline ameliorates arginine deficiency during enteral but not parenteral feeding in neonatal piglets. Am J Physiol 277: E223-31.

6. Wu G, Jaeger LA, Bazer FW, Rhoads JM (2004) Arginine deficiency in preterm infants: Biochemical mechanisms and nutritional implications. J Nutr Biochem 15: $442-51$.

7. Freitas HR, Pereira AS, Ramos TS (2015) The Effects of Acute/Chronic Glutamine and Glutamine Peptide Supplementation on the Performance and Immune Function in Young Active Adult Athletes. Curr Nutri Food Sci 11: 315-22.

8. Burton BK (1998) Inborn errors of metabolism in infancy: a guide to diagnosis. Pediatrics 102: E69.

9. Wilcken B, Wiley V, Hammond J, Carpenter K (2003) Screening newborns for inborn errors of metabolism by tandem mass spectrometry. N Engl J Med 348: 2304-12.

10. Garg U, Dasouki M (2006) Expanded newborn screening of inherited metabolic disorders by tandem mass spectrometry: Clinical and laboratory aspects. Clin Biochem 39: 315-32.

11. McHugh DMS, Cameron CA, Abdenur JE, Abdulrahman M, Adair O, et al. (2011) Clinical validation of cutoff target ranges in newborn screening of metabolic disorders by tandem mass spectrometry: A worldwide collaborative project. Gene Med 13: 230-54.

12. Ristoff E, Larsson A (2007) Inborn errors in the metabolism of glutathione. Orphanet J Rare Diseases 2: 16.

13. Finkelstein JD (2006) Inborn errors of sulfur-containing amino acid metabolism. J Nutr 136: 1750S-4.

14. Watkins D, Rosenblatt DS (2011) Inborn errors of cobalamin absorption and metabolism. Am J Med Genet C Semin Med Genet 157: 33-44.

15. Leonard JV, Morris AA (2000) Inborn errors of metabolism around time of birth. Lancet 356: 583-7.

16. Raghuveer TS, Garg U, Graf WD (2006) Inborn errors of metabolism in infancy and early childhood: an update. Am Fam Physician 73: 1981-90.

17. Rubaltelli FF, Bonafèb L, Tanguccic M, Spagnoloc A, Dania C (1998) Epidemiology of Neonatal Acute Respiratory Disorders. A multicenter study on incidence and fatality rates of neonatal acute respiratory disorders according to gestational age, maternal age, pregnancy complications and type of delivery. Italian Group of Neonatal Pneumology. Biol Neonate 74: 7-15.

18. Levine EM, Ghai V, Barton JJ, Strom CM (2001) Mode of delivery and risk of respiratory diseases in newborns. Obstet Gynecol 97: 439-42.

19. Lydon-Rochelle M, Holt VL, Easterling TR, Martin DP (2001) Risk of uterine rupture during labor among women with a prior cesarean delivery. N Engl J Med 345: 3-8

20. Bernardi JR, Pinheiro TV, Mueller NT, Goldani HAS, Gutierrez MRP, et al. (2015) Cesarean delivery and metabolic risk factors in young adults: a Brazilian birth cohort study. Am J Clin Nutr 102: 295-301.

21. Barber EL, Lundsberg LS, Belanger K, Pettker CM, Funai EF, et al. (2011) Indications Contributing to the Increasing Cesarean Delivery Rate. Obstet Gynecol 118: $29-38$.

22. Ecker J (2013) Elective cesarean delivery on maternal request. JAMA 309: 1930-6.

23. Cole FS, Hamvas A, Nogee LM (2001) Genetic disorders of neonatal respiratory function. Pediatr Res 50: 157-62.

24. Ferkol T, Leigh M (2006) Primary Ciliary Dyskinesia and Newborn Respiratory Distress. Semin Perinatol 30: 335-40.

25. Porto AM, Coutinho IC, Correia JB, Amorim MM (2011) Effectiveness of antenatal corticosteroids in reducing respiratory disorders in late preterm infants: randomised clinical trial. BMJ 342: d1696.

26. Kinsella JP, Cutter GR, Walsh WF, Gerstmann DR, Bose CL, et al. (2006) Early inhaled nitric oxide therapy in premature newborns with respiratory failure. N Engl J Med 355: 354-64.

27. Bhatia J (2006) Fluid and electrolyte management in the very low birth weight neonate. J Perinatolo 26: S19-21.

28. Andreoli SP (2004) Acute Renal Failure in the Newborn. Semin Perinato 28: 112-23.

29. Gouyon JB, Guignard JP (2000) Management of acute renal failure in newborns. Pediatri Nephrol 14: 1037-44.

30. Thies KC, Boos K, Müller-Deile K, Ohrdorf W, Beushausen T, et al. (2000) Ventricular flutter in a neonate-severe electrolyte imbalance caused by urinary tract infection in the presence of urinary tract malformation. J Emerg Med 18: 47-50.

31. Martinerie L, Pussard E, Foix-L’Hélias L, Petit F, Cosson C, et al. (2009) Physiological partial aldosterone resistance in human newborns. Pediatr Res 66: 323-8.

32. Diogo MC, Conceição C, Jacinto JNM, Pamplona J, Reis J (2015) CNS injury in acquired metabolic and hydroelectrolytic disorders: a pictorial review of neuroimaging findings. ECR 2015 doi. 10.1594/ecr2015/C-0342.

33. deVeber G, Andrew M, Adams C, Bjornson B, Booth F, et al. (2001) Cerebral sinovenous thrombosis in children. N Engl J Med 345: 417-23.

34. Amiel-Tison C (1968) Neurological evaluation of the maturity of newborn infants. Arch Dis Childhood 43: 89-93.

35. Breslau N, Chilcoat HD, Johnson EO, Andreski P, Lucia VC (1999) Neurologic soft signs and low birthweight: their association and neuropsychiatric implications. Biol Psychiatry 47: 71-9.

36. Leviton A, Nelson KB (1992) Problems with Definitions and Classifications of Newborn Encephalopathy. Pediatr Neurol 8: 85-90. 
37. Smit BJ, Kok JH, Vulsma T, Briët JM, Boer K, et al. (2000) Neurologic development of the newborn and young child in relation to maternal thyroid function. Acta Paediatr 89: 291-5.

38. Chiriboga CA, Brust JC, Bateman D, Hauser WA (1999) Dose-response effect of fetal cocaine exposure on newborn neurologic function. Pediatrics 103: 79-85.

39. Dammann O, Leviton A, Gappa M, Dammann CE (2005) Lung and brain damage in preterm newborns, and their association with gestational age, prematurity subgroup, infection/inflammation and long term outcome. BJOG 112: 4-9.

40. Mirmiran M, Barnes PD, Keller K, Constantinou JC, Fleisher BE, et al. (2004) Neonatal Brain Magnetic Resonance Imaging Before Discharge Is Better Than Serial Cranial Ultrasound in Predicting Cerebral Palsy in Very Low Birth Weight Preterm Infants. Pediatrics 114: 992-8.

41. Miller SP, McQuillen PS, Hamrick S, Xu D, Glidden DV, et al. (2007) Abnormal brain development in newborns with congenital heart disease. N Engl J Med 357: 1928-38.

42. Zhu C, Kang W, Xu F, Cheng X, Zhang Z, et al. (2009) Erythropoietin Improved Neurologic Outcomes in Newborns With Hypoxic-Ischemic Encephalopathy. Pediatrics 124: e218-26.

43. Duffner PK, Caggana M, Orsini JJ, Wenger DA, Patterson MC, et al. (2009) Newborn Screening for Krabbe Disease: the New York State Model. Pediatr Neurol 40: $245-52$.

44. Mattson MP, Gleichmann M, Cheng A (2008) Mitochondria in Neuroplasticity and Neurological Disorders. Neuron 60: 748-66.

45. Kim SU (2004) Human neural stem cells genetically modified for brain repair in neurological disorders. Neuropathology 24: 159-71.

46. AAP - American Academy of Pediatrics (1985) Nutritional Needs of Low-Birth-Weight Infants. Pediatr 75: 5.

47. Rigo J, Senterre J (2006) Nutritional needs of premature infants: Current Issues. J Pediatrics 149: S80-8.

48. do Nascimento MB, Issler H (2003) Breastfeeding: making the difference in the development, health and nutrition of term and preterm newborns. Revista Do Hospital Das Clínicas 58: 49-60.

49. Wilson DC, Cairns P, Halliday HL, Reid M, McClure G, et al. (1997) Randomised controlled trial of an aggressive nutritional regimen in sick very low birthweight infants. Arch Dis Child Neonatal 77: F4-11.

50. VanderVeen DK, Martin CR, Mehendale R, Allred EN, Dammann O, et al. (2013) Early Nutrition and Weight Gain in Preterm Newborns and the Risk of Retinopathy of Prematurity. PLoS ONE 8: e64325.

51. Fischer CJ, Maucort-Boulch D, Essomo Megnier-Mbo CM, Remontet L, Claris O (2014) Early parenteral lipids and growth velocity in extremely-low-birthweight infants. Clin Nutr 33: 502-8.

52. Singh RH, Rohr F, Frazier D, Cunningham A, Mofidi S, et al. (2014) Recommendations for the nutrition management of phenylalanine hydroxylase deficiency. Genet Med 16: 121-31.

53. Guesnet P, Alessandri JM (2011) Docosahexaenoic acid (DHA) and the developing central nervous system (CNS) - Implications for dietary recommendations. Biochimie 93: 7-12.

54. Lucas A, Morley R, Cole TJ (1998) Randomised trial of early diet in preterm babies and later intelligence quotient. BMJ 317: $1481-7$.

55. Carter BS, Leuthner SR (2003) The ethics of withholding/withdrawing nutrition in the newborn. Semin Perinatol $27: 480-7$.

56. Triunfo S, Lanzone A (2015) Impact of maternal under nutrition on obstetric outcomes. J Endocrinol Invest 38: 31-8.

57. Sonne S, Shekhawat PS, Matern D, Ganapathy V, Ignatowicz L (2012) Carnitine Deficiency in OCTN2-/- Newborn Mice Leads to a Severe Gut and Immune Phenotype with Widespread Atrophy, Apoptosis and a Pro-Inflammatory Response. PLoS ONE 7: e47729.

58. Kasana S, Din J, Maret W (2015) Genetic causes and gene-nutrient interactions in mammalian zinc deficiencies: Acrodermatitis enteropathica and transient neonatal zinc deficiency as examples. J Trace Elem Med Biol 29: 47-62.

59. McLimore HM, Phillips AK, Blohowiak SE, Pham DQD, Coe CL, et al. (2013) Impact of Multiple Prenatal Risk Factors on Newborn Iron Status at Delivery. J Ped HematolOncol 35: 473-77.

60. Maldonado-Cedillo BG, Díaz-Ruiz A, Montes S, Galván-Arzate S, Ríos C, et al. (2015) Prenatal malnutrition and lead intake produce increased brain lipid peroxidation levels in newborn rats. Nutr Neurosci.

61. Ojha S, Robinson L, Yazdani M, Symonds ME, Budge H (2013) Brown adipose tissue genes in pericardial adipose tissue of newborn sheep are downregulated by maternal nutrient restriction in late gestation. Pediatr Res 74: 246-51.

62. Tudehope D, Vento M, Bhutta Z, Pachi P (2013) Nutritional Requirements and Feeding Recommendations for Small for Gestational Age Infants. J Pediatr 162: S81-9.

63. Lapillonne A, O’Connor DL, Wang D, Rigo J (2013) Nutritional Recommendations for the Late-Preterm Infant and the Preterm Infant after Hospital Discharge. J Pediatr 162: S90-100.

64. Valentine CJ, Puthoff TD (2007) Enhancing parenteral nutrition therapy for the neonate. Nutr Clin Pract 22: 183-93.

65. Beecroft C, Martin H, Puntis JW (1999) How often do parenteral nutrition prescriptions for the newborn need to be individualized? Clin Nutr 18: 83-5.

66. Horn W, Popow C, Miksch S, Kirchner L, Seyfang A (2002) Development and evaluation of VIE-PNN, a knowledge-based system for calculating the parenteral nutrition of newborn infants. Artif Intell Med 24: 217-28.

67. Yeung MY, Smyth JP, Maheshwari R, Shah S (2003) Evaluation of standardized versus individualized total parenteral nutrition regime for neonates less than 33 weeks gestation. J Paediatr Child Health 39: 613-7.

68. Riskin A, Shiff Y, Shamir R (2006) Parenteral nutrition in neonatology-to standardize or individualize? Isr Med Assoc J 8: 641-5.

69. Moukarzel A (2009) Chromium in Parenteral Nutrition: Too Little or Too Much? Gastroenterology 137: S18-28.

70. Reynolds AP, Kiely E, Meadows N (1994) Manganese in long term paediatric parenteral nutrition. Arch Dis Child 71: 527-8.

71. Aschner JL, Aschner M (2005) Nutritional aspects of manganese homeostasis. Mol Aspects Med 26: 353-62.

72. Shike M (2009) Copper in Parenteral Nutrition. Gastroenterology 137: S13-7.

73. Albers MJ, Steyerberg EW, Hazebroek FW, Mourik M, Borsboom GJ, et al. (2005) Glutamine Supplementation of Parenteral Nutrition Does Not Improve Intestinal Permeability, Nitrogen Balance, or Outcome in Newborns and Infants Undergoing Digestive-Tract Surgery: Results From a Double-Blind, Randomized, Controlled Trial. Ann Surg 241: 599-606. 
74. Kelly DA (2010) Preventing parenteral nutrition liver disease. Early Hum Dev 86: 683-7.

75. de Meijer VE, Gura KM, Le HD, Meisel JA, Puder M (2009) Fish Oil-Based Lipid Emulsions Prevent and Reverse Parenteral Nutrition-Associated Liver Disease: The Boston Experience. J Parenter Enteral Nutr 33: 541-7.

76. Gura KM, Duggan CP, Collier SB, Jennings RW, Folkman J, et al. (2006) Reversal of Parenteral Nutrition-Associated Liver Disease in Two Infants With Short Bowel Syndrome Using Parenteral Fish Oil: Implications for Future Management. Pediatrics 118: e197-201.

77. Hodge D, Puntis J (2002) Diagnosis, prevention, and management of catheter related bloodstream infection during long term parenteral nutrition. Arch Dis Child Fetal Neonatal Ed 87: F21-4.

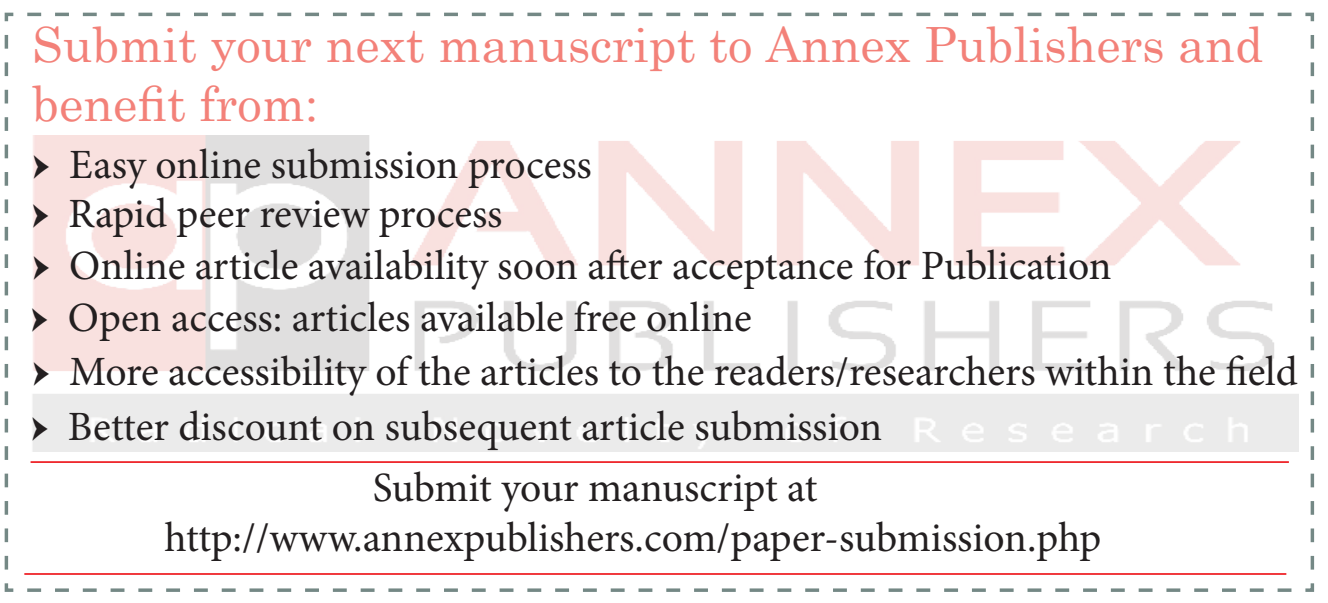

